\section{Treasure of Psusennes}

Now that the sarcophagus of Pharaoh Psusennes found on the site of the ancient Tanis (NATURE, February 24, p. 300 ; March 9, p. 382) has been emptied of its mummy and associated jewellery, it has been possible to form a more just estimate of the magnitude of the find. It is regarded as one of the richest discoveries ever made after that of the tomb of Tutankhamen (The Times, March 7). In this collection of remarkably beautiful jewellery, some of the necklaces, as described, are outstanding. One, for example, is composed of two heavy bars of gold supporting a centre-piece in the form of a golden lotus, which is so heavy, it is said, as to emit a gong. like note when the necklace is shaken. Another necklace consists of several huge pieces of lapis lazuli with gold clasps, on which there is an inscription saying that the King had had made for him a necklace which never would be equalled. This necklace scales the remarkable weight of $12 \mathrm{lb}$. Among other objects of jewellery in the find are mentioned further necklaces, two bracelets, golden slippers with a golden case, pins and studs. All the antiquities found, with the exception of the granite sarcophagus, are being transferred to the Cairo Museum, where they will be placed on exhibition forthwith.

\section{Meteorology in British East Africa}

THE director of the British East African Meteorological Service, Mr. A. Walter, describes the work achieved by his Service in 1938 in his annual report for that year. Although described by him as an extremely difficult year, no hint of this would be obtained from a consideration only of the work achieved and the preparations made for extending and improving the activities of future years. Many of the staff fell sick because it had been impracticable for them to take the vacation leave to which they were entitled, and the training of all grades of staff had to be maintained; it was estimated that this would have to be continued for another five years before each section of the Service could become a fully efficient and self-contained unit.

There is much of interest both on the climatological and synoptic sides in this report, and evidence that important contributions to the understanding of meteorological processes are being made. During the course of the year the whole region, which includes Kenya, Tanganyika, Uganda and Zanzibar, has been divided up into zones characterized by peculiarities in the seasonal distribution of rainfall. Seven such zones were found sufficient to cover broadly the observed range of variation, and have been made the basis of a division of the country into forecast areas, which are shown on a map (p. 27). Both daily and weekly forecasts have been appreciated by the resident population and by visitors, an evidence of this interest being the suggestions received for increasing their frequency and extending their range. The weekly forecasts are based mainly on the relative positions of the high- and low-pressure systems on either side of the tropics and the probable changes in the main wind currents connected with them.
They are described as an unqualified success, a fact which is modestly explained as being due to the circumstance that the effects of high or low pressure appearing off the west coast of Africa are generally felt about a week later in the tropical regions of East Africa.

Many planters have stated that their work is planned in accordance with the indications of the weekly forecasts. Local eccentricities of response to general changes are, however, an obstacle to accurate forecasting here as elsewhere, and it is stated (p. 25) that small short-period variations of pressure, temperature and upper winds are showing a significance which would be considered out of all proportion to their magnitude and duration in the meteorology of temperate regions. This report deserves to be regarded as a model for a young progressive meteorological service in the tropics.

\section{Suggested Grid in the United States}

CONFERENCEs have recently beèn taking place in Washington with the officials of some fifty large public utility companies operating in the eastern part of the United States to explore the possibilities of constructing a series of high-voltage lines interconnecting the larger generating plants and powerconsuming centres in this area, including both private and public developments. According to the Electrical Review of February 9, although up to the present no definite plan has actually been made public, the proposals include connecting links that would make it possible to interchange power whenever necessary between such major load centres as Boston, New York, Philadelphia, Washington, Buffalo, Cleveland, Detroit, Chicago, St. Louis, and possibly Birmingham. Connexions would be made with all major generating stations, both steam and hydro-electric, without regard to whether they are controlled by private capital, municipalities, or the Federal Government.

According to preliminary estimates, the construction would cost approximately $£ 100,000,000$. Objections to the plan have been raised owing to the ample generating capacity now in existence or under construction in each of the localities to meet possible future demands. It is also contended that the expenditure of such a large amount would impose an unnecessary financial burden upon consumers of electricity. The advocates of the scheme take the view that the future growth of power demand will be at an accelerating rate and that the rate of construction can be adjusted to actual needs for the new facilities. They are also understood to be relying strongly on the national defence argument, on the assumption that, even though temporarily uneconomic, the Grid can be justified as a safeguard against the power shortages experienced by American industry during the War of 1914-18.

\section{New Radio Transmitter}

Almost unnoticed in the unsettled international atmosphere that existed last August, an extraordinary radio transmitter was inaugurated in the pocket republic of Andorra, which bestrides a small section 